\title{
Association between quantity and duration of snowfall and risk of myocardial infarction
}

\author{
Nathalie Auger MD MSc, Brian J. Potter MDCM MSc, Audrey Smargiassi PhD, Marianne Bilodeau-Bertrand MSc, \\ Clément Paris MSc, Tom Kosatsky MD MPH
}

Cite as: CMAJ 2017 February 13;189:E235-42. doi: 10.1503/cmaj.161064

CMAJ Podcasts: author interview at https://soundcloud.com/cmajpodcasts/161064-res

See related article at www.cmaj.ca/lookup/doi/10.1503/cmaj.170022

\begin{abstract}
BACKGROUND: Although aggregate data suggest a link between snowfall and myocardial infarction (MI), individual risk has yet to be assessed. We evaluated the association between quantity and duration of snowfall and the risk of MI using nonaggregated administrative health data.
\end{abstract}

METHODS: We used a case-crossover study design to investigate the association between snowfall and hospital admission or death due to $\mathrm{Ml}$ in the province of Quebec, Canada, between November and April during 1981-2014. The main exposure measures were quantity (in cen- timetres) and duration (in hours) of snowfall by calendar day. We computed odds ratios (ORs) and 95\% confidence intervals (Cls) for the association between daily snowfall and MI, adjusted for minimum daily temperatures.

RESULTS: In all, 128073 individual hospital admissions and 68155 deaths due to MI were included in the analyses. The likelihood of MI was increased the day after a snowfall among men but not among women. Compared with $0 \mathrm{~cm}$, $20 \mathrm{~cm}$ of snowfall was associated with an OR of 1.16 for hospital admission
(95\% Cl 1.11-1.21) and 1.34 for death (95\% Cl 1.26-1.42) due to MI the following day among men. Corresponding ORs among women were 1.01 (95\% Cl 0.951.07 ) and 1.04 (95\% Cl 0.96-1.13). Similar but smaller associations were observed for snowfall duration ( $0 \mathrm{~h}$ v. $24 \mathrm{~h}$ ) and MI.

INTERPRETATION: Both the quantity and duration of snowfall were associated with subsequent risk of hospital admission or death due to MI, driven primarily by an effect in men. These data have implications for public health initiatives in regions with snowstorms.
M yocardial infarction (MI) is a leading cause of morbidity and death. ${ }^{1,2}$ Ischemic heart disease accounted for an estimated 6 million years lived with disability and 8 million deaths worldwide in 2013 alone. ${ }^{3,4}$ However, MI prevention is challenging, in part because known risk factors explain only a fraction of cases. Determinants such as advanced age, smoking and diabetes are well established, ${ }^{2,5}$ but environmental risk factors, including the contribution of weather, are not well characterized. Many countries with a high incidence of MI have climates where extreme weather is common. ${ }^{4}$ Much attention has been given to temperature, since exposure to excessive heat increases the risk of hospital admission and death due to MI. ${ }^{6}$ New data suggest that cold temperatures may be associated with an even greater risk of death, ${ }^{7}$ in addition to documented peaks in $\mathrm{MI}$ incidence during winter months. ${ }^{6,8-11}$ Associations with other weather conditions, including snowstorms, however, have received less attention.
Snowstorms could affect the risk of MI, given the evidence that snow-related exertion, including shovelling, can excessively strain the cardiovascular system in susceptible individuals. ${ }^{12-14}$ Snowfall is flagged as a possible MI risk factor in northern countries, ${ }^{9,10,15,16}$ but evidence based on aggregate patient data is conflicting. ${ }^{9,10,12,15-20}$ Because the analysis of aggregate data can result in a loss of statistical power ${ }^{21}$ and carries a risk of ecologic bias, ${ }^{22}$ conclusive evidence of an association between snowfall and $\mathrm{MI}$ has yet to be established. Extreme weather patterns, including blizzards, are predicted to increase with climate change, ${ }^{23}$ thus, an increased risk of $\mathrm{MI}$ in connection with snowfall has clear public health implications.

We undertook an analysis of the likelihood of hospital admission or death due to MI following snowstorms using environmental and administrative health data for individuals in the province of Quebec, Canada, over a period of more than 2 decades. 


\section{Methods}

\section{Study design}

We designed a time-stratified case-crossover study to test whether snowfall was associated with $\mathrm{MI}$ in Quebec, a northern region between the 45 th and 62 nd latitudes characterized by

Table 1: Distribution of myocardial infarctions the day after a snowfall and according to patient characteristics

\begin{tabular}{|c|c|c|}
\hline Variable & $\begin{array}{c}\text { No. }(\%) \text { of } \\
\text { hospital admissions } \\
n=128073\end{array}$ & $\begin{array}{c}\text { No. }(\%) \\
\text { of deaths } \\
n=68155\end{array}$ \\
\hline \multicolumn{3}{|l|}{ Quantity of snow, cm } \\
\hline 0 & $84271(65.8)$ & $44547(65.4)$ \\
\hline $1-4$ & $32234(25.2)$ & $17041(25.0)$ \\
\hline $5-9$ & $6556(5.1)$ & $3793(5.6)$ \\
\hline $10-19$ & $3801(3.0)$ & $2199(3.2)$ \\
\hline$\geq 20$ & $1211(0.9)$ & $575(0.8)$ \\
\hline \multicolumn{3}{|l|}{ Duration of snow, $\mathrm{h}$} \\
\hline 0 & $51838(40.5)$ & $23394(34.3)$ \\
\hline $1-2$ & $9995(7.8)$ & $4651(6.8)$ \\
\hline $3-5$ & $10623(8.3)$ & $5175(7.6)$ \\
\hline $6-11$ & $15188(11.9)$ & $7693(11.3)$ \\
\hline$\geq 12$ & $14031(11.0)$ & $7052(10.3)$ \\
\hline Not available & $26398(20.6)$ & $20190(29.6)$ \\
\hline \multicolumn{3}{|l|}{ Sex } \\
\hline Men & $79150(61.8)$ & $39106(57.4)$ \\
\hline Women & $48923(38.2)$ & $29049(42.6)$ \\
\hline \multicolumn{3}{|l|}{ Age, yr } \\
\hline$<55$ & $22247(17.4)$ & $5546(8.1)$ \\
\hline $55-64$ & $24031(18.8)$ & $10044(14.7)$ \\
\hline $65-74$ & $31838(24.9)$ & $18102(26.6)$ \\
\hline$\geq 75$ & 49957 (39.0) & $34463(50.6)$ \\
\hline $\begin{array}{l}\text { Cardiovascular } \\
\text { comorbidity }^{\star}\end{array}$ & $101254(79.1)$ & $7103(46.2)$ \\
\hline $\begin{array}{l}\text { Cardiovascular risk } \\
\text { factort }\end{array}$ & 89491 (69.9) & $3340(21.7)$ \\
\hline \multicolumn{3}{|l|}{ Material deprivation $\ddagger$} \\
\hline Wealthy & 44255 (34.6) & $14401(34.6)$ \\
\hline Middle income & 37062 (28.9) & $11261(27.0)$ \\
\hline Poor & $32946(25.7)$ & $10503(25.2)$ \\
\hline \multicolumn{3}{|l|}{ Period } \\
\hline 1981-1988 & - & $26503(38.9)$ \\
\hline 1989-1998 & $61915(48.3)$ & $24686(36.2)$ \\
\hline 1999-2008 & $46293(36.1)$ & $12812(18.8)$ \\
\hline 2009-2014 & 19865 (15.5) & $4154(6.1)$ \\
\hline
\end{tabular}

*Includes heart, cerebrovascular, arterial, other cardiovascular disease. Data on deaths are for 15381 deaths from 2000 onward.

†Includes hypertension, diabetes, obesity, dyslipidemia, smoking/chronic obstructive pulmonary disease. Data on deaths are for 15381 deaths from 2000 onward. $\ddagger D$ ata on deaths are for 41652 deaths from 1989 onward. cold winters with subzero temperatures. Case-crossover designs are ideal when the event (MI) is acute and occurs shortly after the exposure (snowfall)..$^{24}$ The case-crossover design is a variant of the case-control study, with the principle difference that cases serve as their own controls. ${ }^{25}$ Instead of matching cases to other individuals, the case is defined as the calendar day that the MI occurred, and the case day is matched to nearby control days when MI did not occur. The weather for case days is subsequently compared with the weather for control days. Because each MI patient is their own control, characteristics such as smoking, socioeconomic status, comorbidity and season are identical between cases and controls. Thus, the case-crossover design automatically adjusts for both known and unknown confounders. ${ }^{25}$ As such, weather is the primary characteristic that differs between cases and controls.

\section{Data sources}

We analyzed hospital admissions and deaths due to MI in Quebec from 1981 to 2014 using 2 different health administrative databases. We restricted data to the months of November through April, because snowfalls are rare during the other months. We obtained individual hospital admission records for MI from MED-ÉCHO (the provincial hospital discharge database) from 1989 (when collection of data in MED-ÉCHO began) to 2014 regardless of residency. Data on deaths due to MI were obtained from death registration certificates for Quebec residents between 1981 and 2013.

Detailed data on weather conditions, including daily snowfalls and temperatures, were obtained from Environment Canada for 18 meteorologic stations representative of each health region of the province. ${ }^{26}$ Regional weather data were matched directly to the region of residence.

\section{Patient population}

For cases, we identified individuals with MI using diagnostic codes of the International Classification of Diseases (ICD-9 code 410 and ICD-10 codes 121-I22). We included patients for whom MI was a reason for the hospital admission or the primary cause of death. For deaths, the case day was defined by the date of death. For hospital admissions, the case day was the date of presentation to the emergency department. For the $17 \%$ of patients who were admitted directly without initially presenting to an emergency department, the first day of the hospital admission was used as the case day.

We identified the sex and age $(<55,55-64,65-74, \geq 75 \mathrm{yr})$ for all MIs. We used ICD codes to determine if cardiovascular comorbidity (heart, cerebrovascular, arterial, other cardiovascular disease) or risk factors (hypertension, diabetes, obesity, dyslipidemia, tobacco/chronic obstructive pulmonary disease) were present (Appendix 1, available at www.cmaj.ca/lookup/suppl/ doi:10.1503/cmaj.161064/-/DC1). Data on cardiovascular comorbidities and risk factors were obtained from other causes of hospital admission in MED-ÉCHO, or from secondary causes of death in the death registration certificates. For deaths, data on secondary causes became available in 2000 . We determined the level of material deprivation using an index of neighbourhood income, 
education and employment from census data linked with the postal code. ${ }^{27}$ We determined the tertile of material deprivation but could do so only beginning in 1989 , when this indicator became available.

We selected controls using a time-stratified approach, ${ }^{24}$ such that control days were the same day of the week in the same calendar month as case days. For example, for a case day on a Friday in the first week of January, the control days were all remaining Fridays in January of the same year. Each case therefore had up to 4 controls. The time-stratified method for selecting controls minimizes bias due to seasonality, temporal trends in weather or medical care, and effects of the day of week. ${ }^{24,28}$ Also, bias due to unidirectional sampling is avoided by selecting controls before and after the date of the case. ${ }^{24}$

\section{Exposure}

Quantity of snowfall was defined as the total number of centimeters of snow during a calendar day, available as daily counts. Duration was defined as the total number of hours of snowfall during the day, computed from hourly data. To ensure that snowfall was measured before the occurrence of $\mathrm{MI}$, we defined the primary exposure as the quantity or duration of snowfall during the calendar day before hospital admission or death.

As secondary exposures, we evaluated the quantity and duration of snow on the same calendar day as the MI, as well as snowfall 2 and 3 days before the MI. Both quantity and duration of snowfall were measured as continuous variables, expressed using splines with knots at the 5th, 50th, and 95th percentiles. To evaluate cumulative effects, we further analyzed 0, 1 and 2-3 consecutive days of snowfall of $5 \mathrm{~cm}$ or more (or $6 \mathrm{~h}$ or longer). This lag covers potentially delayed effects of snowfall, or delayed presentation for care.

The coldest daily temperature expressed as splines was used as a covariate in all analyses, with knots at the same percentiles.

\section{Statistical analysis}

The primary analysis was conducted for all individuals, and secondarily stratified according to sex, age and presence of cardiovascular comorbidity or risk factors. We considered that men might be at different risk for MI than women, both a priori and because of a potentially greater propensity for shovelling. We also sought to determine whether characteristics such as age and cardiovascular comorbidity modified the risks associated with snowfall. We used conditional logistic regression to estimate odds ratios (ORs) and 95\% confidence intervals (Cls) for the association between quantity (or duration) of snowfall and hospital admission (or death) due to MI the following day. Similarly, we estimated associations with MI events on the same day and 2 days following a snowfall, as well as the number of consecutive days of snowfall. We adjusted all models for the coldest daily temperature.

To ensure that associations were not masked by periods with relatively little snowfall, we carried out sensitivity analyses for the months of December through February. We verified the asso-

\section{A: Quantity of snowfall}
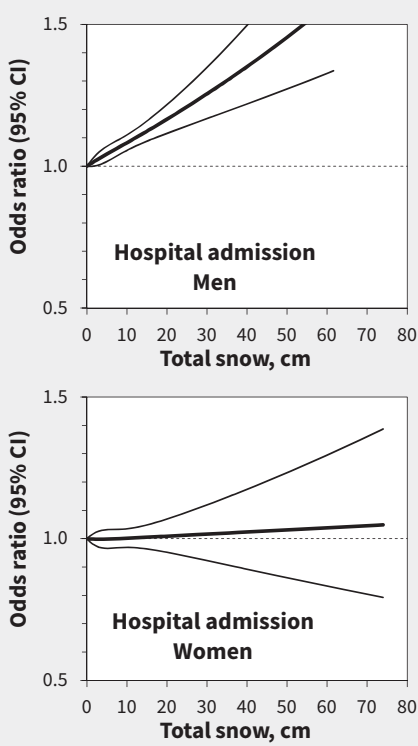
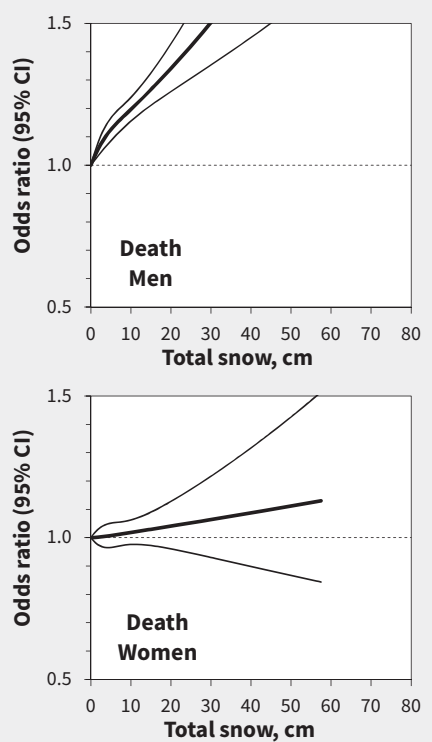

\section{B: Duration of snowfall}
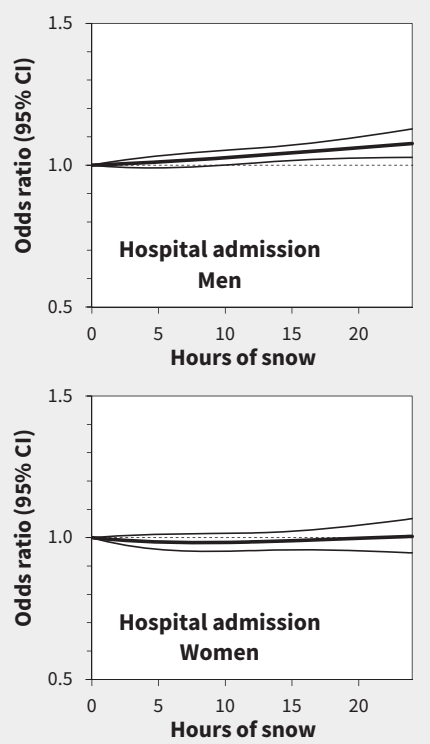
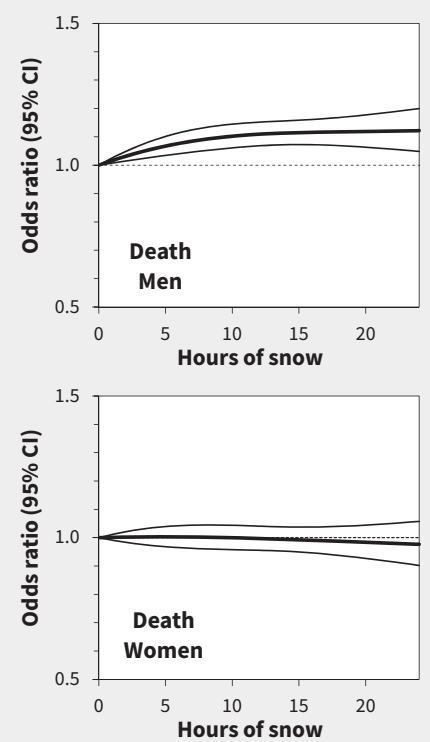

Figure 1: Association between (A) quantity and (B) duration of snowfall and hospital admission or death due to myocardial infarction (MI) among men and women the day after a snowfall. Odds ratios (central lines) and 95\% confidence intervals (outer bands) were adjusted for temperature. Panels for duration of snowfall exclude $\mathrm{Ml}$ events with missing data on duration. Values above 1.0 indicate an increased risk of hospital admission or death. $\mathrm{Cl}=$ confidence interval. 
ciation between snowfall and MI stratified by tertile of material deprivation using an index of neighbourhood income, education and employment. ${ }^{27}$

We performed analyses with SAS version 9.3 (SAS Institute Inc.) using the restricted cubic spline macro. ${ }^{29}$

\section{Ethics approval}

Given that patient data were de-identified, the institutional review board of the Centre hospitalier de l'Université de Montréal provided a waiver for ethics review.

\section{Results}

In all, 128073 individual hospital admissions and 68155 deaths due to $\mathrm{MI}$ were analyzed for the association with the regionspecific quantity and duration of snowfall. About $60 \%$ of the hospital admissions and deaths involved men (Table 1). One-third of MIs occurred the day following a snowfall, and about $10 \%$ occurred after snowfalls of $5 \mathrm{~cm}$ or more.

Quantity of snowfall was associated with an increased likelihood of hospital admission or death due to MI the following day among

\section{A: Quantity of snowfall}
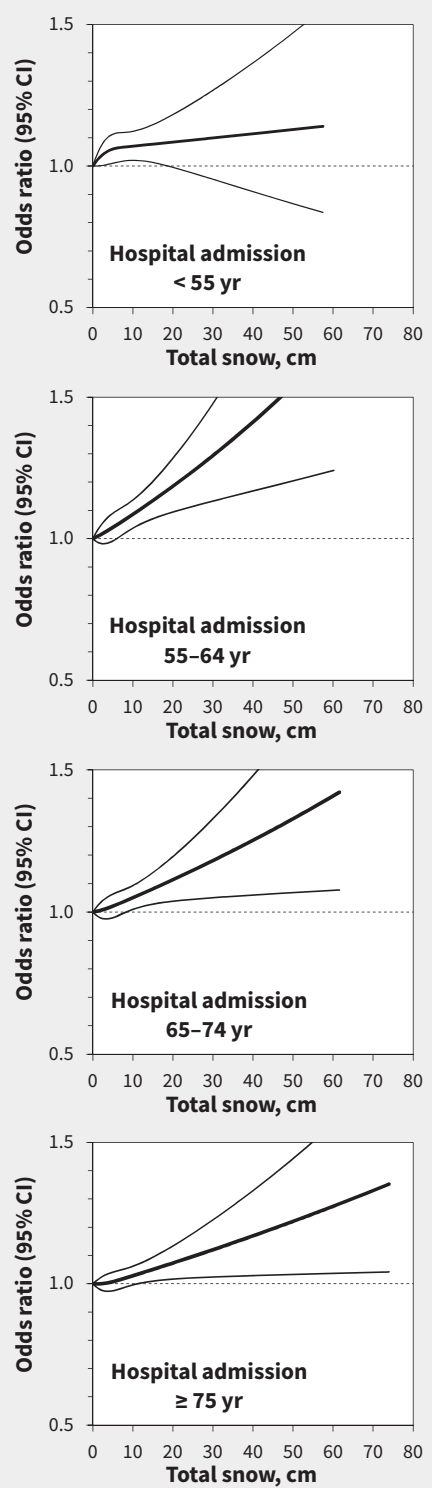
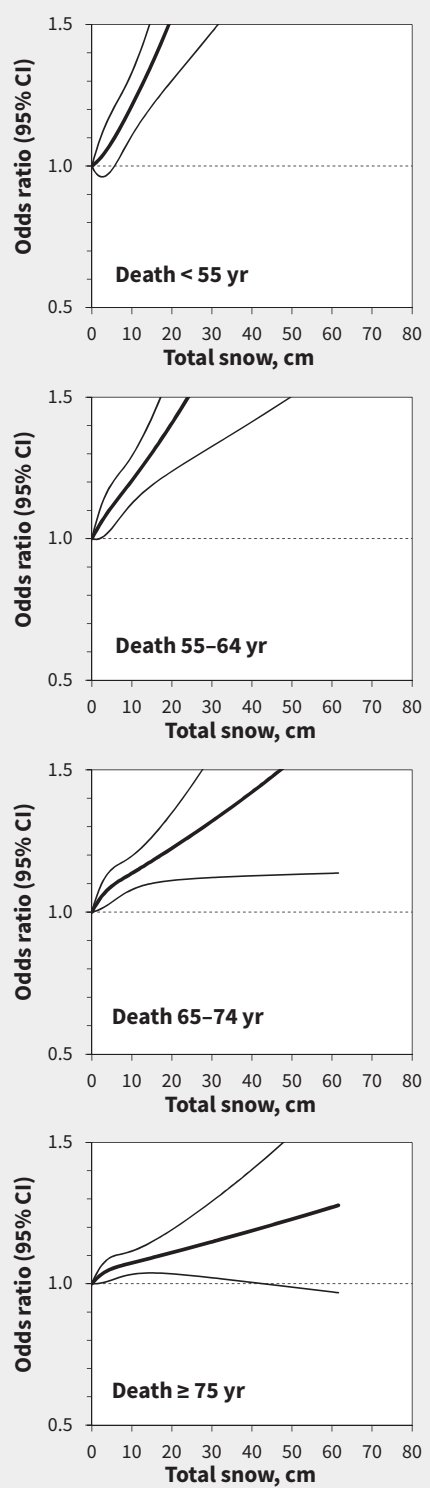

\section{B: Duration of snowfall}
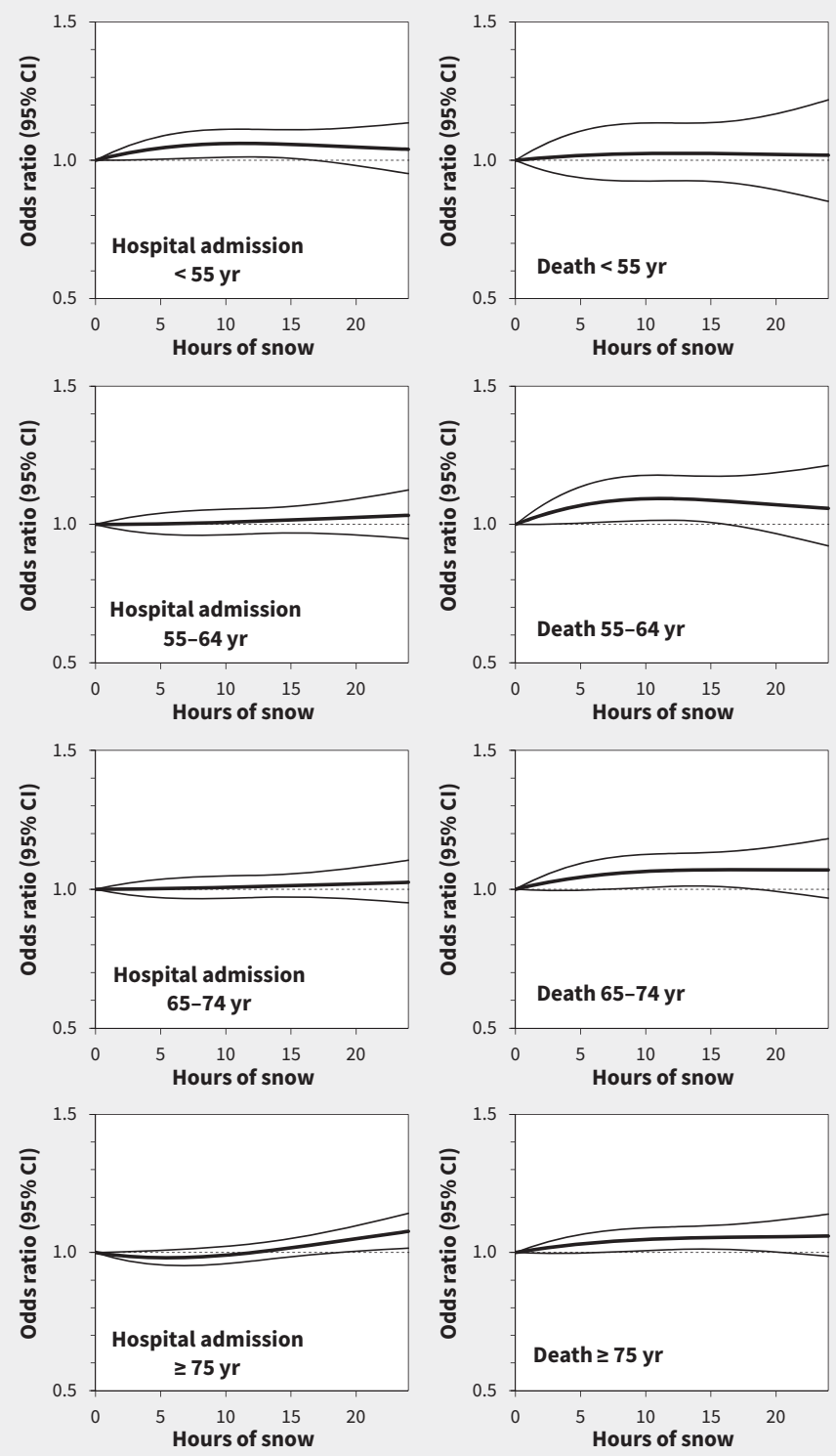

Figure 2: Association between (A) quantity and (B) duration of snowfall and hospital admission or death due to myocardial infarction (MI) by age group the day after a snowfall. Odds ratios (central lines) and 95\% confidence intervals (outer bands) were adjusted for temperature. Panels for duration of snowfall exclude Ml events with missing data on duration. Values above 1.0 indicate an increased risk of hospital admission or death. $\mathrm{Cl}=\mathrm{con}$ fidence interval. 
men (Figure 1). The association between snowfall and MI was stronger among men, and weaker or absent among women. Compared with $0 \mathrm{~cm}, 20 \mathrm{~cm}$ of snowfall was associated with an OR of 1.16 for hospital admission due to $\mathrm{Ml}$ the following day among men $(95 \% \mathrm{Cl}$ 1.11-1.21) but no increased risk among women (OR 1.01, 95\% Cl 0.95-1.07). Similar associations were present for death due to $\mathrm{MI}$ the following day when stratified by sex (men: OR $1.34,95 \% \mathrm{Cl} 1.26-$ 1.42; women: OR $1.04,95 \% \mathrm{Cl} 0.96-1.13$ ). The $p$ values for statistical tests of interaction between sex and quantity of snowfall were $<0.001$ for both hospital admission and death due to MI.
Duration of snowfall was also associated with an increased likelihood of hospital admission or death due to MI among men. Compared with 0 hours, 24 hours of snowfall was associated with an OR of 1.08 for hospital admission (95\% Cl 1.03-1.13) and 1.12 for death (95\% Cl 1.05-1.20) the following day among men. No association with 24 hours of snowfall was observed among women (hospital admission: OR 1.00, 95\% Cl 0.95-1.07; death: $0.95,95 \% \mathrm{Cl} 0.90-1.06)$. The $p$ values for interaction of sex and duration of snowfall were 0.02 for hospital admission and $<0.001$ for death due to MI. Similar results were found for snowfall the

\section{A: Quantity of snowfall}
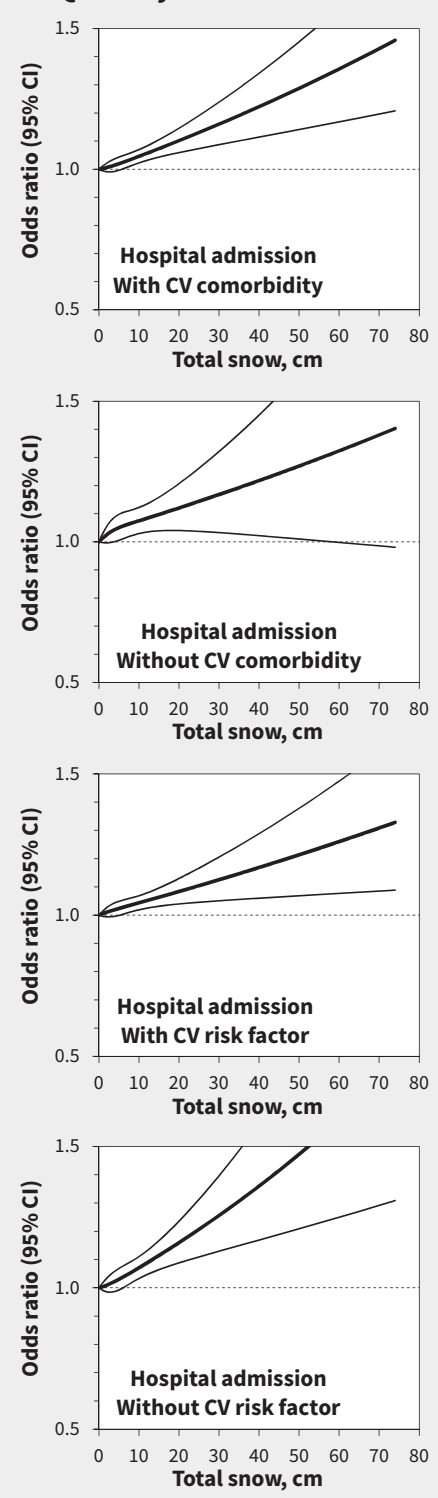

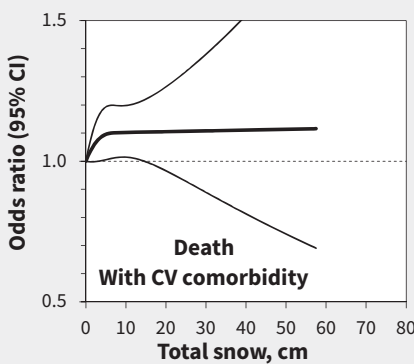

B: Duration of snowfall
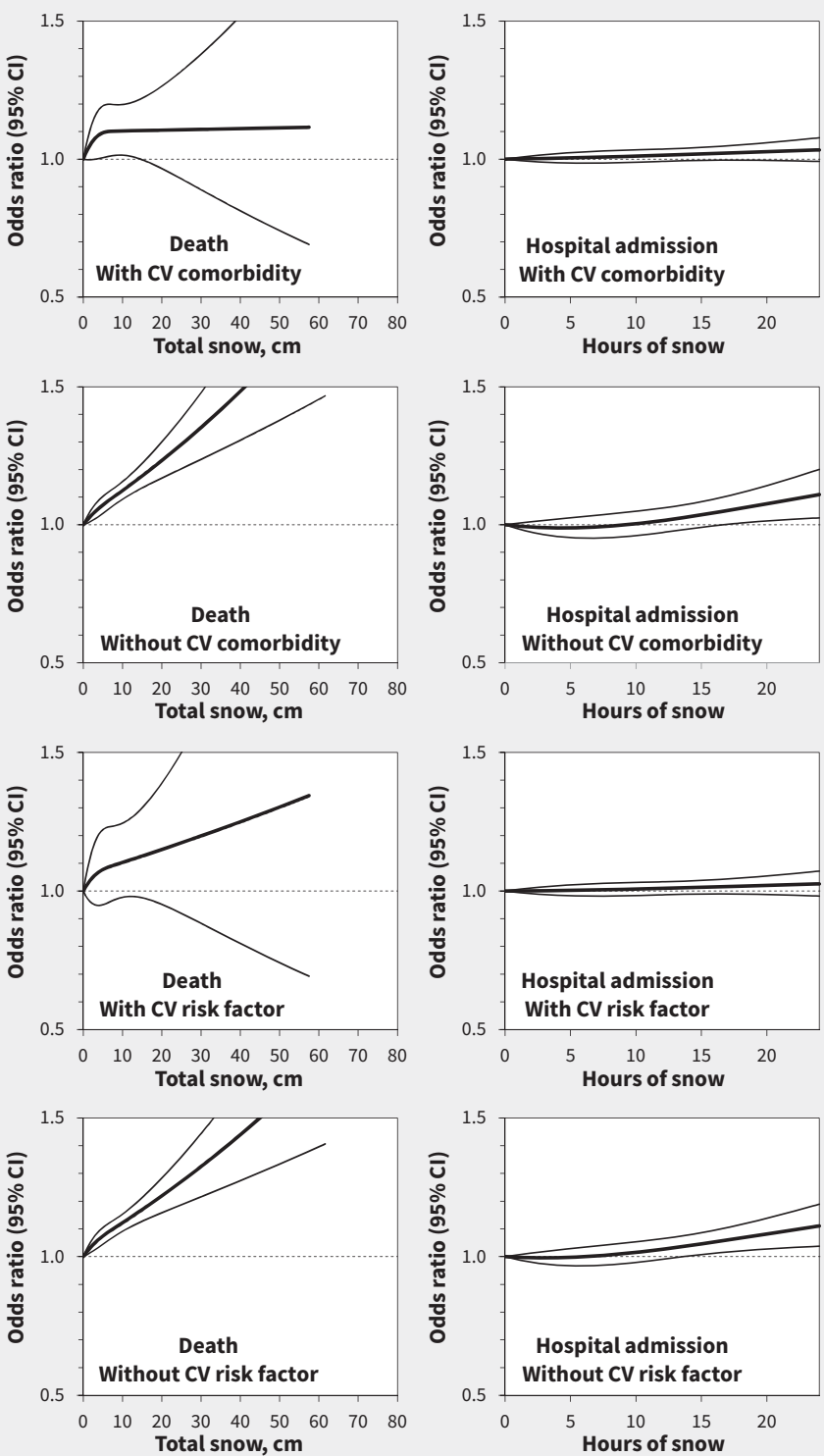
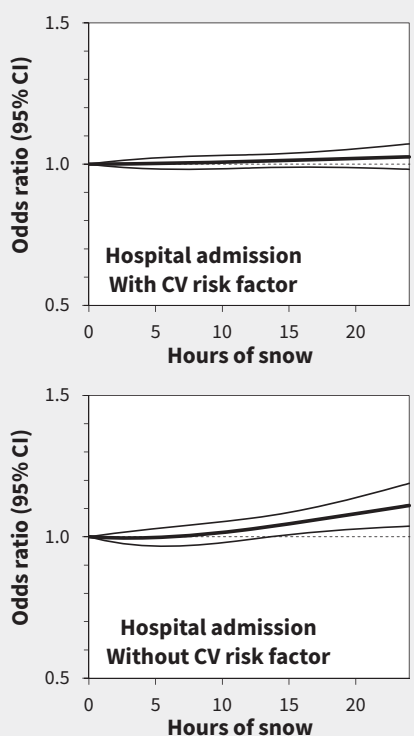
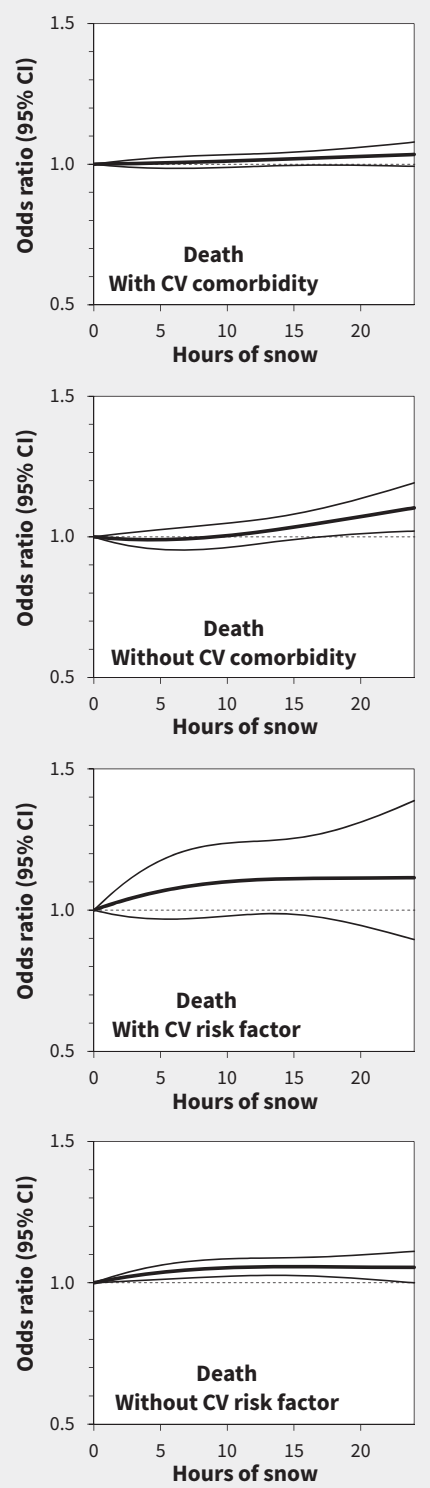

Figure 3: Association between (A) quantity and (B) duration of snowfall and hospital admission or death due to myocardial infarction (MI) the day after a snowfall, according to presence of cardiovascular (CV) comorbidity or risk factors. Odds ratios (central lines) and $95 \%$ confidence intervals (outer bands) were adjusted for temperature. Panels for duration of snowfall exclude MI events with missing data on duration. Values above 1.0 indicate an increased risk of hospital admission or death. $\mathrm{Cl}=$ confidence interval. 
Table 2: Association of number of days of consecutive snowfall with myocardial infarction among men and women

\section{Hospital admission}

No. of MIs

OR $(95 \% \mathrm{CI})$

No. of MIs

Death

\begin{tabular}{|c|c|c|c|c|}
\hline Variable & No. of MIs & OR $(95 \% \mathrm{CI})$ & No. of Mls & OR $(95 \% \mathrm{CI})$ \\
\hline \multicolumn{5}{|l|}{ Men } \\
\hline \multicolumn{5}{|c|}{ No. of days with $\geq 5 \mathrm{~cm}$ of snow } \\
\hline 0 & 66032 & 1.00 (ref) & 32122 & 1.00 (ref) \\
\hline $1^{*}$ & 10820 & $1.06(1.03-1.08)$ & 5684 & $1.14(1.10-1.18)$ \\
\hline 2 or 3 consecutive & 2298 & $1.09(1.04-1.14)$ & 1300 & $1.20(1.12-1.28)$ \\
\hline \multicolumn{5}{|c|}{ No. days of snowfall lasting $\geq 6 \mathrm{~h} \dagger$} \\
\hline 0 & 35414 & 1.00 (ref) & 14170 & 1.00 (ref) \\
\hline $1^{*}$ & 13677 & $1.01(0.98-1.03)$ & 6077 & $1.05(1.02-1.09)$ \\
\hline 2 or 3 consecutive & 13601 & $1.05(1.03-1.08)$ & 6559 & $1.13(1.09-1.17)$ \\
\hline \multicolumn{5}{|l|}{ Women } \\
\hline \multicolumn{5}{|c|}{ No. days with $\geq 5 \mathrm{~cm}$ of snow } \\
\hline 0 & 41414 & 1.00 (ref) & 24427 & 1.00 (ref) \\
\hline $1^{*}$ & 6185 & $0.98(0.95-1.01)$ & 3808 & $1.02(0.98-1.06)$ \\
\hline 2 or 3 consecutive & 1324 & $0.98(0.92-1.04)$ & 814 & $1.08(0.99-1.17)$ \\
\hline \multicolumn{5}{|c|}{ No. days of snowfall lasting $\geq 6 \mathrm{~h} \dagger$} \\
\hline 0 & 22434 & 1.00 (ref) & 11882 & 1.00 (ref) \\
\hline $1^{*}$ & 8481 & $1.01(0.98-1.04)$ & 4654 & $0.98(0.94-1.02)$ \\
\hline 2 or 3 consecutive & 8068 & $1.00(0.97-1.03)$ & 4623 & $0.98(0.94-1.03)$ \\
\hline
\end{tabular}

day of MI (Appendix 2, available at www.cmaj.ca/lookup/suppl/ doi:10.1503/cmaj.161064/-/DC1). There was no association between snowfall and MI 2 or 3 days later.

In analyses stratified by age, there was no compelling evidence that associations were more important in any particular age group (Figure 2). Associations with snowfall were present regardless of the presence of cardiovascular comorbidity or risk factors, although individuals without comorbidity or risk factors had a higher risk of hospital admission with longer durations of snowfall (Figure 3).

The likelihood of MI among men increased with the consecutive number of days of snow (Table 2). Compared with 0 days, 2-3 consecutive days of $5 \mathrm{~cm}$ or more of snowfall was associated with an OR of 1.09 for hospital admission due to $\mathrm{MI}$ among men ( $95 \% \mathrm{Cl} 1.04-1.14)$, whereas 1 day of $5 \mathrm{~cm}$ or more was associated with an OR of $1.06(95 \% \mathrm{Cl} 1.03-1.08)$. Similarly, 2-3 consecutive days of $5 \mathrm{~cm}$ or more was associated with an OR of 1.20 for death due to $\mathrm{MI}$ among men (95\% Cl 1.12-1.28), whereas 1 day of snowfall was associated with an OR of 1.14 (95\% Cl 1.10-1.18). A dose-response trend among men was also present for 2-3 consecutive days of snowfall lasting 6 hours or more. Among women, 2-3 consecutive days of $5 \mathrm{~cm}$ or more of snowfall was not associated with hospital admission (OR $0.98,95 \% \mathrm{Cl} 0.92-1.04$ ) or death (OR 1.08 , 95\% Cl $0.99-$ 1.17) due to $\mathrm{MI}$.
In the sensitivity analyses, data restricted to the months of December through February yielded similar results (Appendix 3). The association between snowfall and MI was present in all deprivation tertiles (Appendix 4). Temperature was not associated with hospital admission or death due to $\mathrm{MI}$ in models adjusted for snowfall (Appendix 5). (Appendices available at www.cmaj.ca/lookup/suppl/doi:10.1503/cmaj.161064/-/DC1.)

\section{Interpretation}

In our analysis of nearly $200000 \mathrm{MI}$ events in the province of Quebec, quantity and duration of snowfall were associated with an increased likelihood of hospital admission or death due to MI. The association was observed among men but not among women and was strongest the day following a snowfall. Two or 3 days of consecutive snowfall increased the risk of MI further. Risks were elevated regardless of age, cardiovascular comorbidity or cardiovascular risk factors. These results call for caution after snowfalls, particularly for men who may be at higher risk, and may have increasing relevance over time, considering climate change and predictions that extreme weather will increase. ${ }^{23}$

Several ecologic studies have highlighted the possibility that snowfall is associated with MI risk. Daily counts of death due to MI were associated with snowfalls in Pennsylvania, Rhode Island and Minneapolis-St. Paul, all located in the northern regions of the 
United States. ${ }^{9,16}$ A correlation between snowfall and incidence of MI was also reported in Switzerland, ${ }^{15}$ which has a climate somewhat comparable to Quebec's. In contrast, the frequency of hospital admission due to MI was not associated with snowfall in a Swedish sample of 382 patients. ${ }^{19}$ Other ecologic analyses similarly failed to find an increased incidence of MI the day of a snowfall, but they may well have been underpowered. ${ }^{17,18,20}$

In our study, the increased risk of hospital admission or death due to MI was primarily among men. We suspect that shovelling was the main mechanism linking snowfall with MI. Men are potentially more likely than women to shovel, particularly after heavy snowfalls. Snow shovelling is a demanding cardiovascular exercise requiring more than $75 \%$ of the maximum heart rate, ${ }^{12,14}$ particularly with heavy loads. ${ }^{14}$ It is a unique activity with both static and dynamic components, involving the Valsalva manoeuvre and increased systolic blood pressure. ${ }^{12,13}$ Intense arm effort, repetitive motion, static upright posture, peripheral vasoconstriction ${ }^{14}$ and greater myocardial afterload all increase the risk of coronary plaque rupture and thrombus formation..$^{12,14}$ Risks may be exacerbated by exposure to cold temperatures, ${ }^{13,14}$ which increases vasoconstriction and blood pressure, and consequently the preload, cardiac output and oxygen demand of the heart. ${ }^{30}$ Sudden exposure to cold temperatures has been shown to lead to sympathovagal activation and arrhythmia, ${ }^{31}$ and breathing cold air has been shown to reduce coronary blood flow. ${ }^{32}$

\section{Limitations}

Although our study represents a large analysis of $\mathrm{Ml}$ in a region where snowfall is common, a number of limitations deserve attention. Use of administrative data to identify MI events may have resulted in misclassification for a proportion of cases. Diagnostic criteria for $\mathrm{MI}$, as well as the sensitivity of biochemical assays for Ml detection, changed during the study period. However, misclassification and evolving diagnostic criteria are unlikely to vary with degree of snowfall, or the short 1-month span within which controls were identified.

We measured snowfall and temperature levels on the basis of regional estimates from weather stations, which may have led to imprecision in the exposure assignment in some cases. We do not have information on sex-specific shovelling habits, the size of areas shovelled or whether snow removal was automated (snow blowers v. manual shovelling). Although these are potentially important considerations, the hypothesis that shovelling is associated with an increased risk of $\mathrm{Ml}$ events among men remains plausible. Some researchers have even reported that cardiac demands are elevated with automated snow removal. ${ }^{12}$

Finally, the generalizability of the findings to areas with different levels of snowfall remains to be investigated.

\section{Conclusion}

Both the quantity and duration of snowfall were associated with subsequent risk of hospital admission or death due to $\mathrm{MI}$ in the province of Quebec, particularly among men. These findings are most likely related to the increased cardiac demands of snow shovelling. Climate change and the predicted increase in the frequency and intensity of winter storms raise the possibil- ity of a greater incidence of MI in the future. Clinicians and public health practitioners should consider awareness campaigns before the winter season to inform individuals of the risk of MI after a snowfall, and possibly advise against shovelling for the most at risk patients.

\section{References}

1. Wang OJ, Wang Y, Chen J, et al. Recent trends in hospitalization for acute myocardial infarction. Am J Cardiol 2012;109:1589-93.

2. Dégano IR, Salomaa V, Veronesi G, et al. Twenty-five-year trends in myocardial infarction attack and mortality rates, and case-fatality, in six European populations. Heart 2015;101:1413-21.

3. GBD 2013 Mortality and Causes of Death Collaborators. Global, regional, and national age-sex specific all-cause and cause-specific mortality for 240 causes of death, 1990-2013: a systematic analysis for the Global Burden of Disease Study 2013. Lancet 2015;385:117-71.

4. Global Burden of Disease Study 2013 Collaborators. Global, regional, and national incidence, prevalence, and years lived with disability for 301 acute and chronic diseases and injuries in 188 countries, 1990-2013: a systematic analysis for the Global Burden of Disease Study 2013. Lancet 2015;386: 743-800.

5. Yusuf S, Hawken S, Ôunpuu S, et al. Effect of potentially modifiable risk factors associated with myocardial infarction in 52 countries (the INTERHEART study): case-control study. Lancet 2004;364:937-52.

6. Bhaskaran K, Hajat S, Haines A, et al. Effects of ambient temperature on the incidence of myocardial infarction. Heart 2009;95:1760-9.

7. Gasparrini A, Guo Y, Hashizume M, et al. Mortality risk attributable to high and low ambient temperature: a multicountry observational study. Lancet 2015;386: 369-75.

8. Spielberg C, Falkenhahn D, Willich SN, et al. Circadian, day-of-week, and seasonal variability in myocardial infarction: comparison between working and retired patients. Am Heart J 1996;132:579-85.

9. Gorjanc ML, Flanders WD, VanDerslice J, et al. Effects of temperature and snowfall on mortality in Pennsylvania. Am J Epidemiol 1999;149:1152-60.

10. Hopstock LA, Fors AS, Bønaa KH, et al. The effect of daily weather conditions on myocardial infarction incidence in a subarctic population: the Troms $\varnothing$ Study 1974-2004. J Epidemiol Community Health 2012;66:815-20.

11. Lin S, Soim A, Gleason KA, et al. Association between low temperature during winter season and hospitalizations for ischemic heart diseases in New York State. J Environ Health 2016;78:66-74.

12. Franklin BA, Hogan $\mathrm{P}$, Bonzheim $\mathrm{K}$, et al. Cardiac demands of heavy snow shoveling. JAMA 1995;273:880-2.

13. Ito M, Yamamoto $\mathrm{T}$, Takaku $\mathrm{K}$, et al. Acute heart failure syndrome associated with snow shoveling. Int Heart J 2012;53:394-5.

14. Sheldahl LM, Wilke NA, Dougherty SM, et al. Effect of age and coronary artery disease on response to snow shoveling. J Am Coll Cardiol 1992;20:1111-7.

15. Goerre S, Egli C, Gerber S, et al. Impact of weather and climate on the incidence of acute coronary syndromes. Int J Cardiol 2007;118:36-40.

16. Baker-Blocker A. Winter weather and cardiovascular mortality in MinneapolisSt. Paul. Am J Public Health 1982;72:261-5.

17. Southern DA, Knudtson ML, Ghali WA, et al. Myocardial infarction on snow days: Incidence, procedure use and outcomes. Can J Cardiol 2006;22:59-61.

18. Persinger MA, Ballance SE, Moland M. Snow fall and heart attacks. J Psychol 1993;127:243-52

19. Ohlson CG, Bodin L, Bryngelsson L, et al. Winter weather conditions and myocardial infarctions. Scand J Soc Med 1991;19:20-5.

20. Gerber Y, Jacobsen SJ, Killian JM, et al. Seasonality and daily weather conditions in relation to myocardial infarction and sudden cardiac death in Olmsted County, Minnesota, 1979 to 2002. J Am Coll Cardiol 2006;48:287-92.

21. Wakefield J. Ecologic studies revisited. Annu Rev Public Health 2008;29:75-90.

22. Webster TF. Bias magnification in ecologic studies: a methodological investigation. Environ Health 2007;6:17. 
23. Pachauri RK, Meyer LA, Barros VR, et al., editors. Climate change 2014: synthesis report. Contribution of Working Groups I, II and III to the Fifth Assessment Report of the Intergovernmental Panel on Climate Change. Geneva: Intergovernmental Panel on Climate Change; 2014:1-151.

24. Levy D, Lumley $T$, Sheppard L, et al. Referent selection in case-crossover analyses of acute health effects of air pollution. Epidemiology 2001;12:186-92.

25. Maclure M, Mittleman MA. Should we use a case-crossover design? Annu Rev Public Health 2000;21:193-221.

26. Auger N, Fraser WD, Smargiassi A, et al. Elevated outdoor temperatures and risk of stillbirth. Int J Epidemiol 2016 May 9. pii: dyw077. [Epub ahead of print].

27. Pampalon R, Hamel D, Gamache P, et al. Validation of a deprivation index for public health: a complex exercise illustrated by the Quebec index. Chronic Dis Inj Can 2014;34:12-22.
28. Janes H, Sheppard L, Lumley T. Case-crossover analyses of air pollution exposure data: referent selection strategies and their implications for bias. Epidemiology 2005;16:717-26.

29. Heinzl H, Kaider A. Gaining more flexibility in Cox proportional hazards regression models with cubic spline functions. Comput Methods Programs Biomed 1997;54:201-8

30. Manou-Stathopoulou V, Goodwin CD, Patterson T, et al. The effects of cold and exercise on the cardiovascular system. Heart 2015;101:808-20.

31. Shattock MJ, Tipton MJ. 'Autonomic conflict': A different way to die during cold water immersion? J Physiol 2012;590:3219-30.

32. Muller MD, Gao Z, Drew RC, et al. Effect of cold air inhalation and isometric exercise on coronary blood flow and myocardial function in humans. J Appl Physiol 2011;111:1694-702.

\section{Competing interests: None declared.}

This article has been peer reviewed.

Affiliations: Centre de recherche du Centre hospitalier de l'Université de Montréal (Auger, Potter, Bilodeau-Bertrand); Institut national de santé publique du Québec (Auger, Smargiassi, Bilodeau-Bertrand, Paris); Division of Cardiology, Department of Medicine (Potter), Centre hospitalier de I'Université de Montréal; Department of Occupational and Environmental Health (Smargiassi), School of Public Health, Université de Montréal, Montréal, Que.; Faculty of Science (Paris), Aix-Marseille Université, Marseille, France; National Collaborating Centre for Environmental Health (Kosatsky), British Columbia Centre for Disease Control, Vancouver, BC

Contributors: Nathalie Auger conceived and designed the study. Marianne Bilodeau-Bertrand and Clément Paris analyzed the data under guidance of Nathalie Auger. Brian Potter, Audrey Smargiassi and Tom Kosatsky helped interpret the results. Nathalie Auger, Brian Potter and Marianne Bilodeau-Bertrand drafted the manuscript, and Audrey Smargiassi, Clément Paris and Tom Kosatsky revised it for critical intellectual content. All of the authors approved the final version of the manuscript to be published and agreed to act as guarantors of the work.

Funding: The study was funded by the Canadian Institutes of Health Research (grant no. MOP-142277) and Fonds de recherche du Québec-Santé (career award no. 25128). Clément Paris was supported by a bursary from the Conseil Régional de Provence-Alpes-Côte-d'Azur.

Accepted: Jan. 4, 2017

Correspondence to: Nathalie Auger, nathalie.auger@inspq.qc.ca 